\title{
REVIEW
}

\section{Solid Platelet Rich Plasma in Corneal Surgery}

Francisco Arnalich • Alejandra E. Rodriguez • Alvaro Luque-Rio •

Jorge L. Alio

Received: February 3, 2016 / Published online: May 14, 2016

(c) The Author(s) 2016. This article is published with open access at Springerlink.com

\section{ABSTRACT}

Abstract: Solid eye platelet-rich plasma (E-PRP) concentrates platelets in a small volume of plasma which contains a high concentration of important growth factors and cell adhesion molecules. These cell adhesion molecules and growth factors occupy a major role in wound healing and enhance the physiological procedure at the site of the injury or the surgery. There are different materials used to tectonically maintain the solid clot attached at the site where treatment is necessary. Although AM may be used for this

Enhanced content To view enhance content for this article go to http://www.medengine.com/Redeem/ 43C4F06037E42EFC.

F. Arnalich

Department of Cornea and Refractive Surgery,

VISSUM, Madrid, Spain

A. E. Rodriguez - A. Luque-Rio

Research and Development Department, VISSUM,

Alicante, Spain

J. L. Alio (ه)

Department of Cornea and Refractive Surgery,

VISSUM, Alicante, Spain

e-mail: jlalio@vissum.com

J. L. Alio

School of Medicine, Miguel Hernandez University, Alicante, Spain purpose, other biomaterials such a bovine pericardium or autologous fibrin membrane are at least as effective with less interdonor variations, no biological hazards, providing a better surgical alternative than the biologically so variable amniotic membrane patch. Solid platelet-rich plasma in the form obtained in ophthalmology, E-PRP, is a reliable and effective surgical coadjuvant to promote corneal wound healing in severe corneal ulcers and corneal perforations, and may be associated with other ocular surface reconstruction procedures.

Funding: Supported in part by a grant from the Spanish Ministry of Science and Innovation, Centro para el Desarrollo Tecnológico Industrial (CDTI), CENIT: "Customized Eye Care", CeyeC (CEN-20091021).

Keywords: Amniotic membrane; Corneal surgery; Fibrin membrane; Platelet-rich plasma; PRP; Tutopatch

\section{INTRODUCTION}

Severe ocular surface disease (OSD) due to thermal and chemical burns, Stevens-Johnson syndrome (SJS), ocular cicatricial pemphigoid (OCP) or other 
conditions currently poses a serious clinical challenge for ophthalmologists' worldwide [1]. In these cases, the corneal epithelial stem cells located in the corneal limbus are destroyed, and physiological healing of the ocular surface may not be possible spontaneously, causing corneal perforation or coverage of the corneal surface by invading neighbouring conjunctival epithelial cells resulting in neovascularization, chronic inflammation, ingrowth of fibrous tissue and stromal scarring. The treatment of ocular surface disorders has a multifactor approach and conventional treatments are often not enough to solve the problem. In patients with severe ocular surface disease, the success of amniotic membrane in treating ulcers and/or perforations is less than $20 \%[2,3]$. Investigators have been searching for a long time for a product that would be similar to tears in composition and activity and, which may incite the regeneration of the tissues affected in ocular surface disorders. Plasma-derived products have shown an important role in the treatment of ocular surface disorders [2-5].

Plasma, unlike serum, does contain clotting proteins of full blood such as fibrinogen, and as platelets are great reservoirs of growth factors, contains a higher concentration of these components than the acellular part of the blood, the serum [6]. Platelet-rich plasma (PRP) is a portion of the plasma fraction of blood having a platelet concentration above baseline. Autologous PRP is obtained by means of double centrifugation, where after the platelets are activated just prior to clinical use. The final concentration is at least $1,000,000$ platelets $/ \mu \mathrm{L}$. The preparation contains platelet-derived growth factors and other molecules considered to have healing properties [7], unlike artificial tears, and have $\mathrm{pH}$, osmolarity and biomechanical properties which resemble natural tears [8].
The eye platelet-rich plasma (E-PRP) used in ophthalmology is a preparation of autologous plasma, rich in platelets, but with a different platelet concentration from the PRP preparation described by Marx et al. [7] in which a double centrifugation is done to concentrate the platelets. The E-PRP uses sodium citrate as an anticoagulant and when necessary calcium chloride is used for the activation of the E-PRP in its solid or clot formulation. Plasma rich in growth factors (PRGF) [9] is another platelet rich preparation in which after a first centrifugation, the platelets are activated using calcium chloride in the liquid or eye drop formulation. PRGF uses a commercial kit to obtain the blood and a specific laboratory centrifuge is used for plasma separation. E-PRP does not require specific devices (Fig. 1).

The E-PRP fabrication is carried out using a one-step centrifugation process and the final platelet concentration depends on whether it will be used as an eye drop for topical application (without activation) or as a clot (activated with calcium chloride), for surgical procedures such as ocular reconstruction or treatment of corneal perforations.

The aim of this review is to comprehensively appraise the state of the art with regard to the use of blood-derived products in corneal surgery.

This article is based on previously conducted studies and does not involve any new studies of human or animal subjects performed by any of the authors.

\section{RATIONALE FOR USE}

Different blood-derived formulations, such as autologous serum, plasma enriched with platelets and preparations rich in growth factors have been used to promote wound 

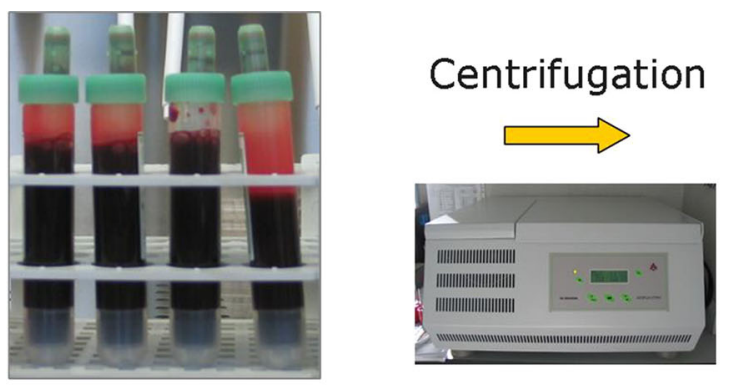

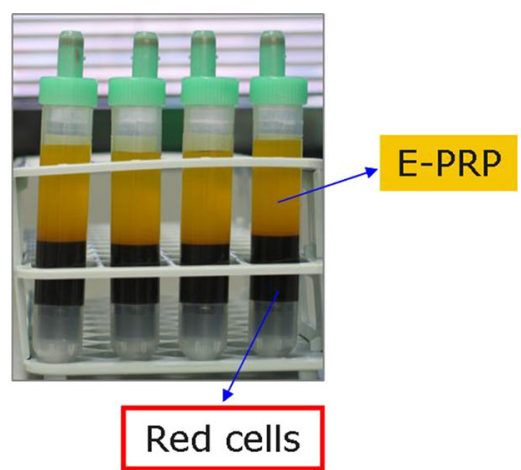

Fig. 1 Obtaining procedure of eye platelet-rich plasma (E-PRP)

healing in multiple tissues. Blood-derived products have demonstrated their capacity to increase healing and stimulate the regeneration of different tissues supplying growth factors and other bioactive molecules that are present in the blood [10].

Serum is the clear fluid that is obtained during blood coagulation after blood cells and clotting proteins have been removed. Since Fox et al. [11] first used autologous serum eye drops in the treatment of keratoconjunctivitis sicca, it has been the preferred blood-derived topical preparation used in the treatment of ocular surface diseases. Autologous serum has been found to be effective in the treatment of persistent epithelial defects [12], neurotrophic ulcers [13], superior limbic keratoconjunctivitis [14] and dry eye conditions such as graft-versus-host disease [15] or after LASIK [16]. Autologous serum has also been used as an adjunctive treatment in ocular surface reconstruction with variable results $[17,18]$. Unlike artificial tears, serum eye drops have $\mathrm{pH}$, osmolarity and biomechanical properties that resemble natural tears, and they are non-preserved. Used topically they supply essential nutrients to the ocular surface such as growth factors, vitamins and bacteriostatic products such as IgG, lysozyme and complement [19]. Therefore, they potentially provide lubrication, and have epitheliotrophic and antimicrobial properties that are not found in commercialised artificial tears.

Plasma, unlike serum, does contain the clotting proteins found in blood itself, such as fibrinogen. Although the plasma itself contains growth factors, platelets are also great reservoirs of growth factors that have the potential to enhance cell proliferation and wound healing. The alpha-granules in platelets contain many bioactive proteins such as epidermal growth factor (EGF), platelet derived growth factor $A B$ (PDGF-AB), vascular endothelial growth factor (VEGF), insulin-like growth factor (IGF-1), transforming growth factor beta (TGF- $\beta$ ), as well as cytokines including proteins such as CD40L and PF4, which promote tissue repair and affect angiogenesis and inflammation [10]. Growth factors released from activated platelets initiate and modulate wound healing in both soft and hard tissues [20, 21]. The plasma also contains concentrated quantities of some important cell-adhesion molecules which promote epithelial migration such as fibrinogen, fibronectin and vitronectin [6]. Laboratory research with different cultured cellular lines such as tendon cells, synovial and skin fibroblasts and corneal epithelial cells, shows the multiple benefits and biological effects of growth factors, including proliferation, differentiation and healing [19, 22-24]. 
Dormant corneal ulcers are persistent epithelial defects that fail to heal in spite of at least 2 weeks of conventional treatment, and are most commonly caused by neurotrophic keratopathy (including metaherpetic disease), dry eye or immunological disorders such as rheumatoid arthritis or ocular cicatricial pemphigoid. In a prospective study, Alió et al. [25] included 26 eyes with dormant corneal ulcers with neurotrophic keratopathy $(n=12)$ (Fig. 2a), herpetic keratopathy $(n=9)$ and ulcers of immunological origin $(n=5)$. They were treated for 15 days with E-PRP eye drops at a dose of six times a day in addition to routine medication. Primary outcome measures were the decrease in size or depth of the corneal ulcer and recovery of vision. Secondary outcome measures were the reduction of discomfort or pain, decrease in conjunctival hyperemia, or conjunctival oedema if present. Significant clinical improvement was found in $92 \%$ of the eyes $(24 / 26)$, with a complete resolution of the ulcer in $50 \%$ of the cases (13/26) (Fig. 2b). Only two eyes did not show significant improvement after the treatment. Reduction in inflammation and decrease of ocular pain were the other parameters that clearly improved in the majority of the cases. Two eyes of two different patients with a recidivant epithelial defect, defined as observation of a new epithelial defect in the same place of the previous ulcer with positive fluorescein staining under slit-lamp examination, occurred after 6 months to 1 year and were treated successfully by keratoplasty. Visual acuity also improved in more than half of the patients, with $31 \%$ of the eyes gaining 1-3 lines of visual acuity, $15 \%$ with an improvement of 4-5 lines of visual acuity, and $12 \%$ with more than 6 lines of improvement. A reduction in inflammation was observed after 1 or 2 weeks, with a decrease in ocular pain. This report showed that E-PRP improved, pain, inflammation and photophobia; enhanced reepithelialisation, promoting corneal wound healing and improving the clinical condition, which in the end, resulted in improved vision in the most of the patients studied.

PRP has been used previously by our group and others in small series of patients to treat several ocular surface problems with good results $[26,27]$.
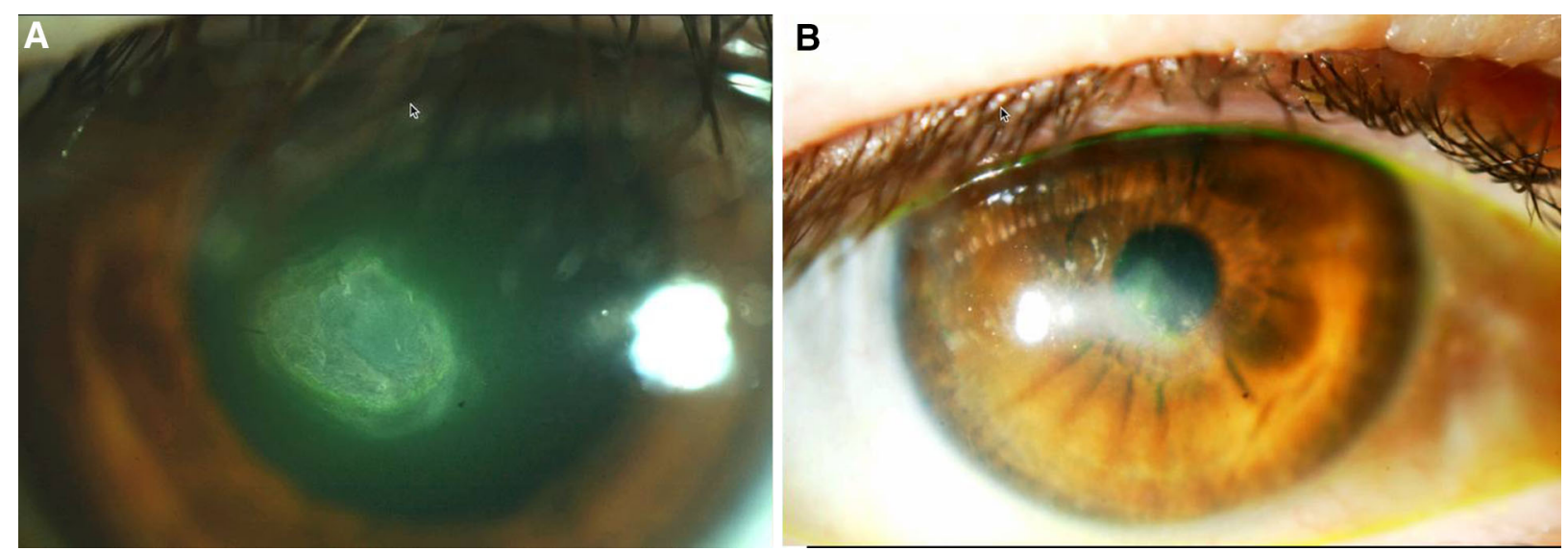

Fig. 2 a Neurotrophic ulcer patient before treatment with eye platelet-rich plasma (E-PRP). b Same patient in a after 1 month of treatment with topical E-PRP 
PLATELET-RICH PLASMA

AS A SURGICAL ADJUVANT TOOL IN SEVERE CORNEAL ULCERS AND PERFORATIONS

E-PRP and PRGF have been successfully used as a component for tissue regeneration procedures such as reconstructive orthopaedic surgery, plastic surgery, and oral and maxillofacial surgery [28-30]. In dental implant surgery the use of autologous platelet-rich clot has been shown to accelerate ossification after a tooth extraction or around titanium implants, with improved success rate and marked reductions in the time required for implant stabilization [31-33].

In articular surgery [34] and tendon repair [35] autologous platelets have also been shown to accelerate healing. Concentrated platelet preparations are also used to induce bone regeneration when prosthetic devices are to be implanted [36] in implant and maxillofacial surgery. Platelets derivatives are also used in traumatology, combined with hydroxyapatite, autologous bone and other biomaterials [37-39].

\section{SOLID E-PRP DESCRIPTION AND PREPARATION}

E-PRP can be used to promote and enhance healing during ocular surface reconstruction procedures or to treat impending perforation or even frank perforations. In theory, clot E-PRP should provide a higher amount of growth factors in an initial burst as well as late synthesis and secretion of growth factors for the remaining 7 days of the lifespan of a platelet [40]. Patients are screened for HVB, HVC and $\mathrm{HIV}$, the presence of active infection is a contraindication for manipulation of blood-derived products in the laboratory.

The manipulation of the blood to prepare autologous E-PRP must be done under sterile conditions using a laminar flow cabin [6]. For this purpose, between 40 and $60 \mathrm{~mL}$ of blood is extracted from the patient just before the surgery. Blood is centrifuged by the one-step process as previously described for the E-PRP eye drop formulation [6]. However in this case, only the plasma in the region of the red cell column is harvested, avoiding the white blood cell layer, the 'buffy coat', in order to avoid the undesirable proinflammatory effects of leucocyte products. One millilitre of E-PRP is placed into each well tissue culture plate and $50-60 \mu \mathrm{l}$ of Braun $^{\circledR} 10 \%$ calcium chloride are added for activation. The mix is homogenized gently using an sterile tip, and placed at $37^{\circ} \mathrm{C}$ in an incubator for half an hour. After that time, the E-PRP clot is formed and it is ready to be applied onto the ocular defect immediately afterwards (Fig. 3). In the E-PRP clot the platelet enrichment corresponds to a number density that is about 2-3 times that of full blood [6].

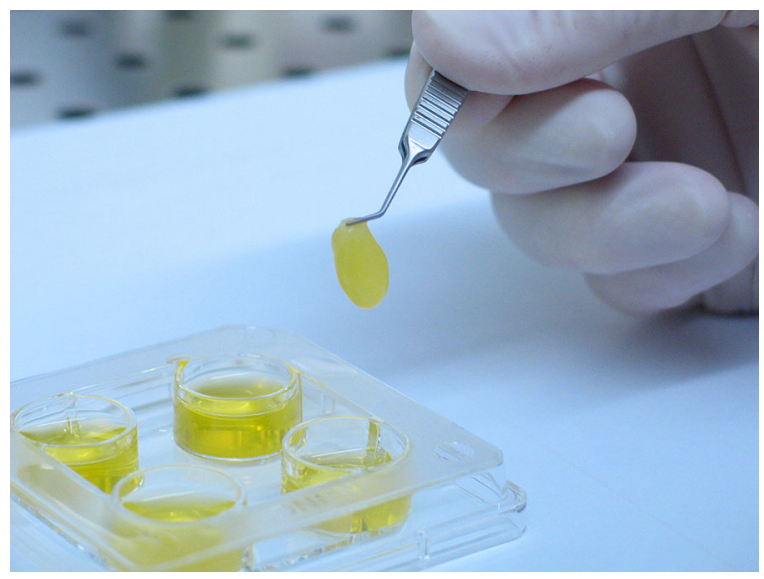

Fig. 3 Aspect of a clot of eye platelet-rich plasma (E-PRP) immediately after its preparation 


\section{SOLID E-PRP COMBINED WITH THE USED OF AMNIOTIC MEMBRANE TRANSPLANTATION}

Ocular surface reconstruction includes limbal autograft or allograft keratoplasty, amniotic membrane transplantation (AMT), sectorial epitheliectomy, etc. Theoretically, the adjuvant use of E-PRP would enhance the regenerative effect of these interventions, by release of growth factors that promote wound healing and decrease inflammation. Other biologically active products such as autologous serum have been used successfully for this purpose [17].

Alió et al. [25] presented a series of cases with perforated eyes or high probability of perforation due to deep chronic corneal ulcers treated with AMT combined with a clot of autologous E-PRP. Surgery consisted of wound debridement, excision and removal of devitalized tissue with a posterior application of AM to the wound site with the epithelial side up. A clot of autologous E-PRP was inserted beneath the $\mathrm{AM}$ to seal the imminent or existing corneal perforation with an increase in the therapeutic effect of the AM (Fig. 4). The membrane was sutured in place to the conjunctiva using a 10-0 nylon suture and a running purse-string suture was applied so that the membrane tightly adhered to the entire corneal surface. The eye was closed with a provisional tarsorrhaphy. Initial outcome measures were the decrease in size or depth of the corneal ulcer and improvement in best-corrected visual acuity. All patients showed an improvement in the size of the ulcer, and $71 \%$ (10/14 eyes) had complete resolution. Vision also improved in $57 \%$ of the cases (8/14 eyes) along with a decrease in inflammation that occurred 1-2 weeks after the surgery. It cannot be ascertained in this kind of ocular surface alterations whether the healing effect of the E-PRP in combination with $\mathrm{AM}$ was higher than using AM alone. However, theoretically, E-PRP use together with AM should additionally encourage corneal wound healing processes and further decrease inflammation due to the effect of E-PRP.

We also have experience (unpublished data) with the use of E-PRP clot in other surgical interventions to restore the ocular surface such as limbal keratoplasty (Fig. 5) with good results, as seen with autologous serum by other authors $[17,18]$. We believe that the prolonged synthesis and release of growth factors by the E-PRP clot provides additional long acting that would increase the benefit of E-PRP over autologous serum [40].

\section{SOLID E-PRP COMBINED WITH THE USE OF BOVINE PERICARDIUM (TUTOPATCH)}

In the previous section we defined the use of combined solid E-PRP and amniotic membrane (AM) for the management of impending or actual perforations. The autologous platelet-rich preparation was used to stimulate tissue regeneration, and to induce epithelial and mesenchymal cells to migrate and proliferate to restore the site of the injury. The role of the AM was to conserve the solid clot attached at the damaged surface. We carried out a pilot study [41] to use a commercially available collagenous membrane obtained from bovine pericardium as an alternative to $\mathrm{AM}$ for the management in emergency cases. This membrane was designed to repair, support and replace the connective tissue. Unlike amniotic membrane, the commercially available bovine pericardium does not need specific authorization to be used as a graft, and 

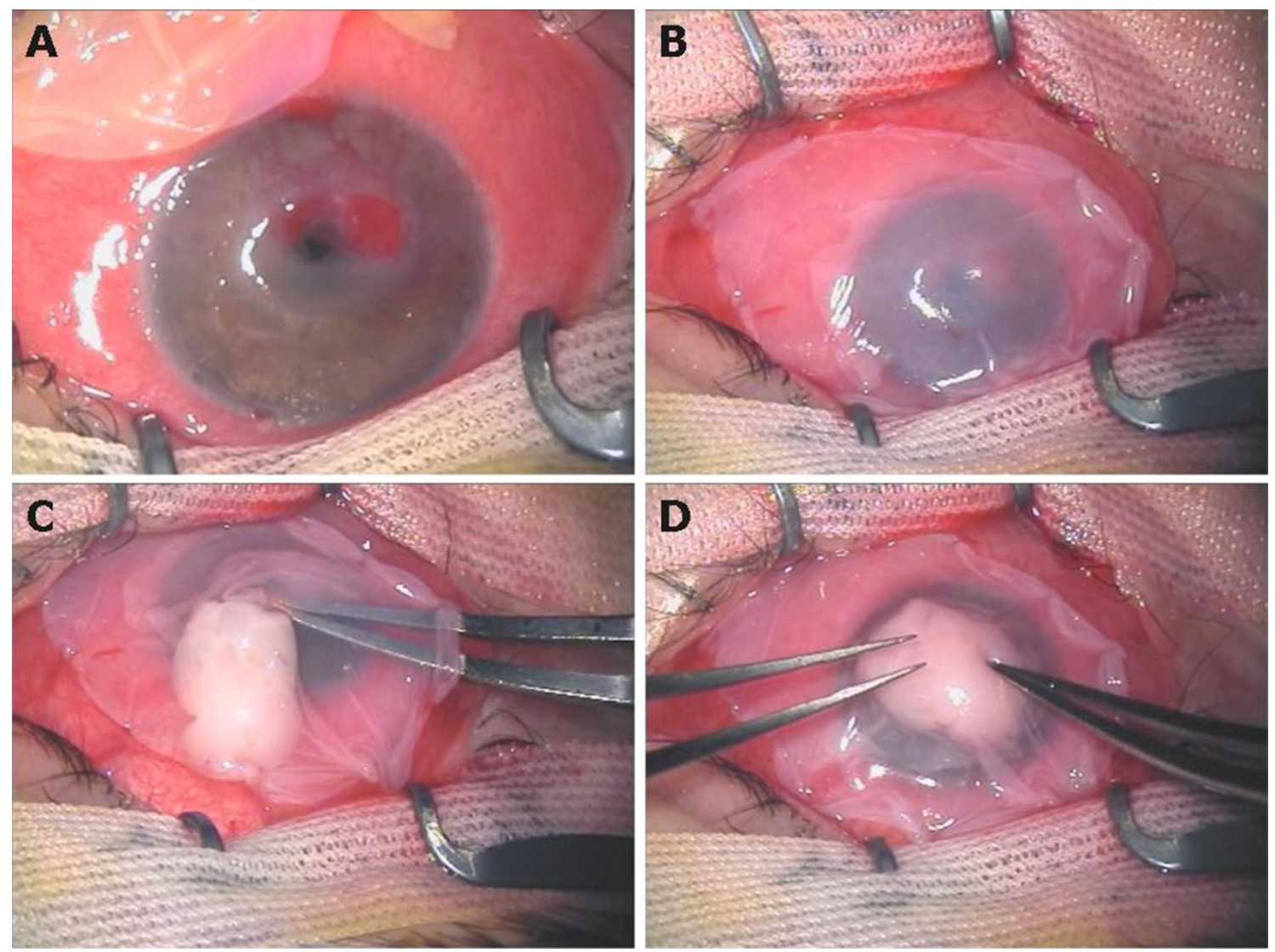

Fig. 4 a Corneal perforation patient before amniotic membrane transplantation (AMT). b Application and partial suture of amniotic membrane on corneal

perforation. $\mathbf{c}$ Placing eye platelet-rich plasma (E-PRP) clot below the AM. d Final result after AMT with E-PRP clot in the perforated eye

it is a completely inert material underwent to a procedure of dehydration, purification, deantigenation and sterilization resulting in an acellullar tissue structure free of pathogens, antigens, prions and any other non-collagen protein. Moreover there are no interdonor variations as it has been observed with amniotic membrane [42].

The bovine pericardium patch used was Tutopatch $^{\circledR} \quad$ (Tutogen Medical GmbH, Neunkirchen, Germany). The use of Tutopatch has been described in cardiovascular surgery [43] for closure of ventricular septal defects, for dural substitution in a variety of neurosurgical procedures [44], and in ophthalmology in cases of patients with orbital fracture where a

reposition of the floor is needed [45]. In patients who undergo enucleation for uveal melanoma, wrapping of hydroxyapatite implants with bovine pericardium has been suggested as a safe alternative with a lower rate of complications and a decreased surgical time compared to other procedures with autologous tissue that needs to be harvested [46]. In cases of glaucoma needing surgery, a double layer of Tutopatch has been used in conjunction with the implantation of a valve Ahmed in a patient with necrotizing scleritis [41].

In our pilot study [41] we included six patients with different types of corneal perforations caused by a chronic corneal 

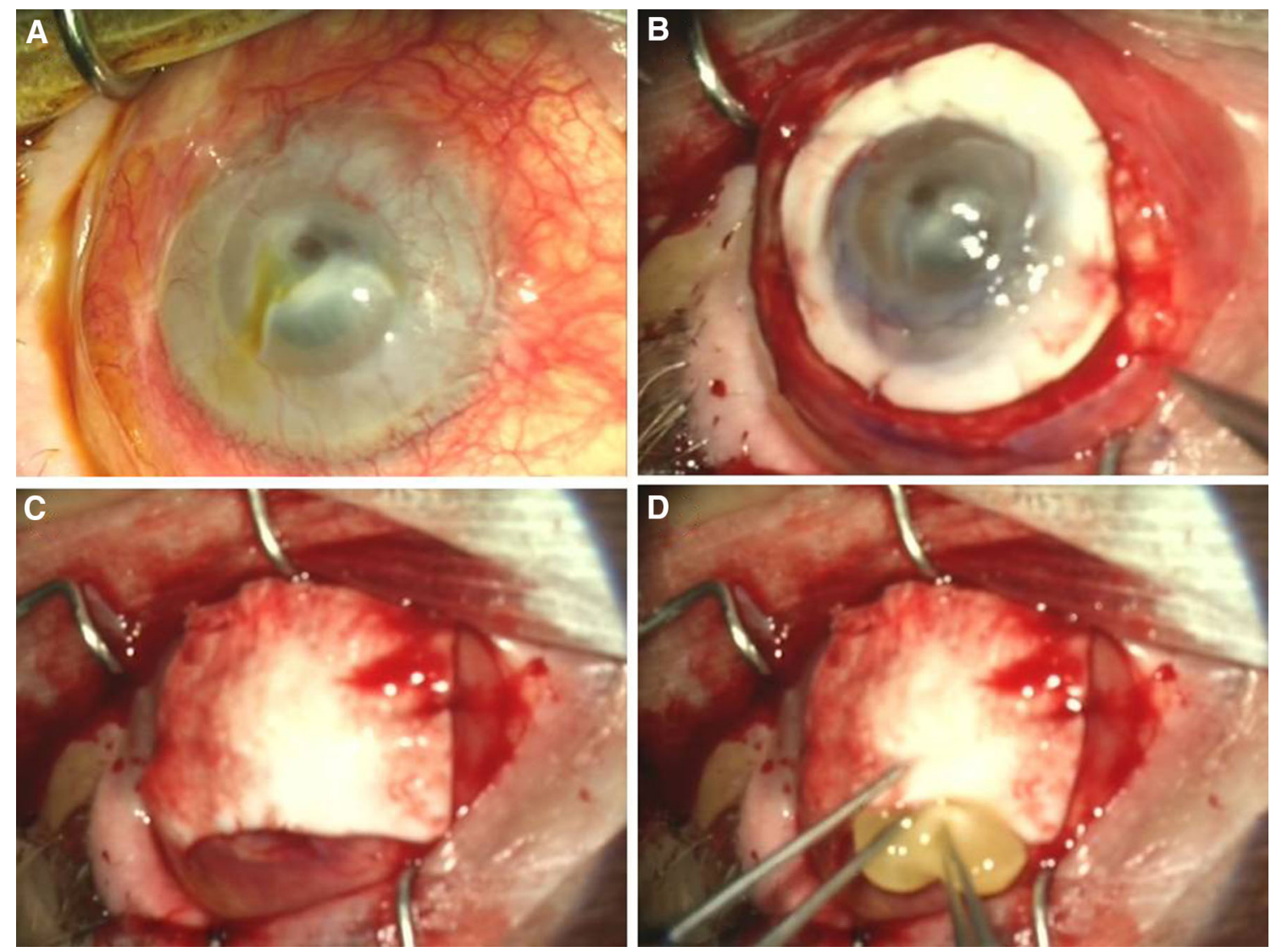

Fig. 5 a Patient with limbar deficiency before surgery. b Limbal keratoplasty before application of eye platelet-rich plasma (E-PRP) clot and collagen membrane. c Placing

Tutopatch on limbal keratoplasty. d Application of E-PRP clot under Tutopatch after limbal keratoplasty

ulcerative disorder. There were three cases of ocular cicatricial pemphigoid, two neurotrophic ulcers and one corneal decompensation. None of them demonstrated signs of active infection at the time of the operation. The eyelids were separated and the epithelium was debrided $1.0-1.5 \mathrm{~mm}$ from the perforation. The pericardial patch was then moistened with an antibiotic solution with $1 \%$ cefuroxime until it became a flexible membrane. The pericardium membrane was then trimmed to conform to the shape of the eye. Then a 10-0 nylon-running suture was used to suture the Tutopatch to the $180^{\circ}$ inferior conjunctiva (Fig. 6). For the preparation of the clots of E-PRP, $1 \mathrm{~mL}$ of the PRP is placed into each four-well tissue culture

plate (Nunc), and $50 \mathrm{~mL}$ of $10 \%$ calcium chloride (Braun) are added to each well for activation. Clots of E-PRP were then placed into the site of the perforation and over the debrided area beneath the collagenous membrane. Additional sutures were used to fix the membrane to the remainder of the conjunctiva. At the end of the procedure, a temporary and partial tarsorrhaphy was performed to allow observation of the central cornea with the slit lamp. In all cases a firm non hypotonic ocular globe was assessed by digital examination. No evidence of infection or inflammation was detected in any of the cases. Two or 3 weeks after the surgery, the temporal tarsorrhaphy was opened in all patients and the 

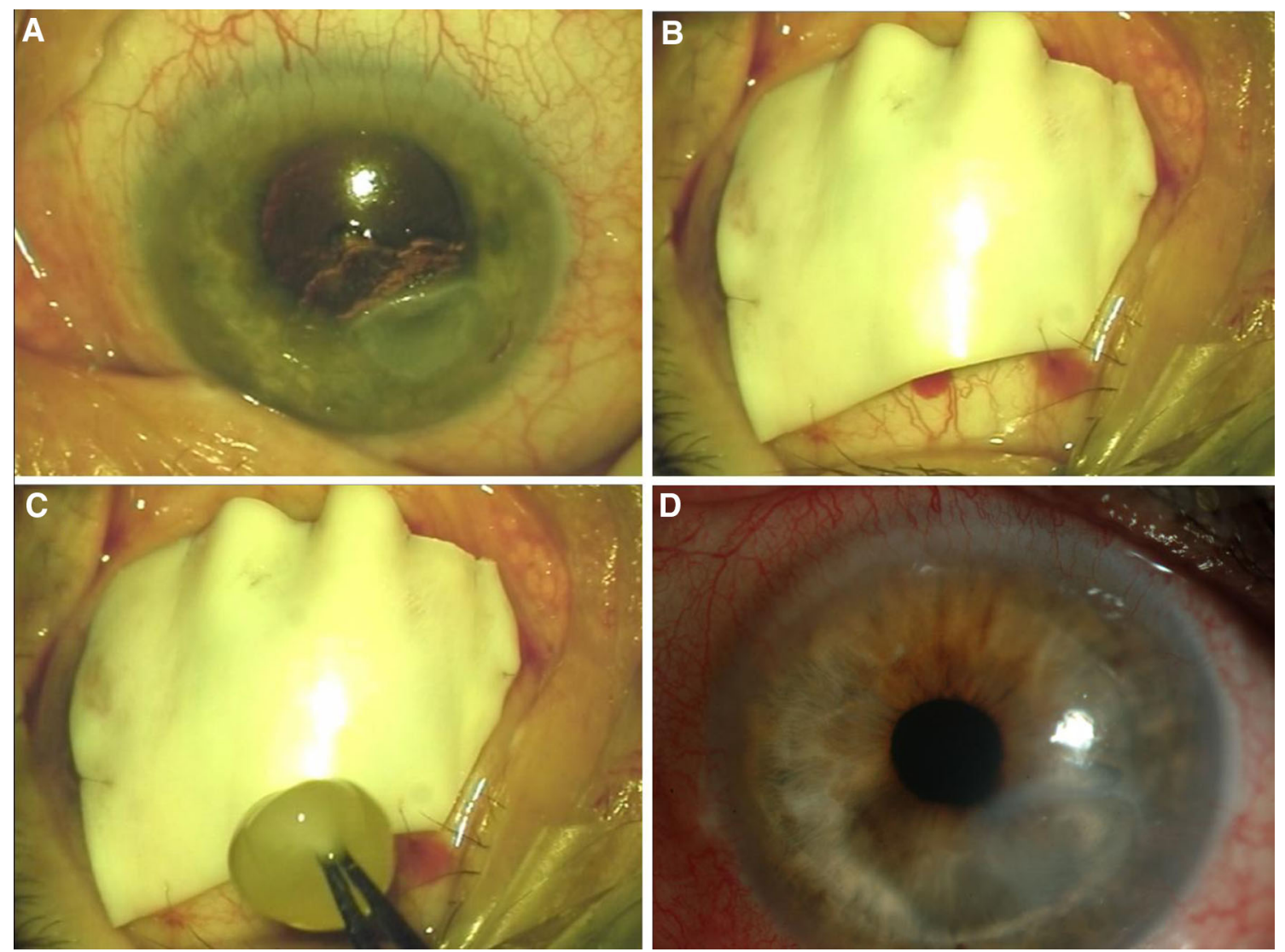

Fig. 6 a Neurotrophic corneal ulcer with high risk of perforation. b Application of Tutopatch on the ulcer and partial suture. $\mathbf{c}$ Placing E-PRP clot under the collagen membrane. $\mathbf{d}$ Eye of the same patient, 1 month postoperatively

ocular surface was analyzed. In all cases the corneal perforation was sealed up with no evidence of leakage even when moderate pressure was applied to the globe. No relapses of the ulcerative corneal condition or perforation in five of the cases before the performance of the definitive corneal grafting surgery. Only patient 6 , with severe ocular cicatricial pemphigoid and long history of limbal stem cell deficiency with two previous limbal stem cell transplantation suffered a relapse, and a penetrating keratoplasty was performed 1 month after the Tutopatch procedure.

In summary, both E-PRP clot and bovine pericardium can be successfully combined for the management of all the perforations to take advantage of the effect of E-PRP growth factors and the tectonic properties of the Tutopatch, although the number of patients in the study was reduced. This technique has a low biological risk, and can be proposed as an accessible and natural active solution for the urgent management of perforated corneal ulcers.

\section{SOLID E-PRP COMBINED WITH THE USE OF AN AUTOLOGOUS FIBRIN MEMBRANE}

Corneal perforation constitutes a major ophthalmic emergency necessitating surgical intervention because of the severity and major consequences, such as infection, severe 
anatomical distortion of the anterior segment of the eye, retinal detachment, phthisis bulbi and total blindness [47]. These perforations are the result of trauma and ulcerative diseases of different conditions.

Perforation can be managed with the use of sealants such as cyanoacrylate [48], or using different types of patches such as autologous conjunctival flaps [49], or more commonly multilayer AM transplants [50]. Corneal grafting is usually delayed as much as possible to improve the clinical condition and therefore surgical success [51]. Moreover, in many cases there may not be corneal tissue readily available. AM transplants can be considered now as one of the preferred options to treat corneal perforations, especially if the size of the perforation is big for ocular adhesives like cyanoacrylate. However, AM is an uneven biological tissue with different properties and efficacy depending on the method of processing and preservation [42]. It may introduce major biological hazards such as viral contaminants and prions [50], and in some countries needs specific authorization to be used as a grafting tissue.

For all these reasons we developed an autologous fibrin patch, 100\% autologous, which can be easily handled because its consistency and thickness (Fig. 7), and can be used with E-PRP as clot as we had done with AM [6] or Tutopatch [41]. The fibrin strands of the patch can bind to the clot and at the same time to the stromal collagen fibers of the cornea, thus contributing to sealing the defect. The fibrin patch and platelet clot gradually disappear over the wound, constituting an autologous, physiological and biological active solution for corneal perforation.

Preparation of the autologous fibrin membrane requires a glass beaker previously sterilized. Working inside a laminar flow hood,

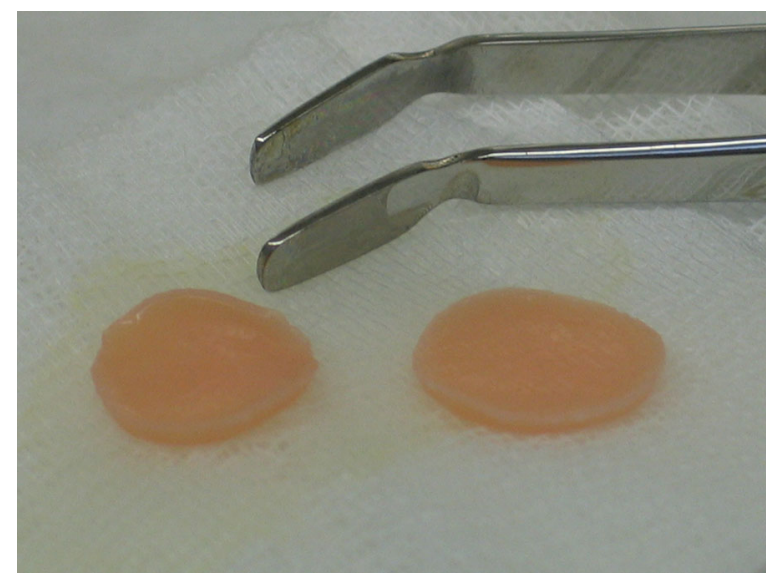

Fig. 7 Aspect of two pieces of fibrin membrane immediately after their preparation

$5 \mathrm{~mL}$ of platelet-poor plasma are placed in the beaker together with $500 \mu \mathrm{L}$ of $10 \%$ calcium chloride and $1 \mathrm{~mL}$ of previously prepared autologous thrombin. Autologous thrombin is obtained by activation of $3 \mathrm{~mL}$ of E-PRP with $300 \mu \mathrm{L}$ of $10 \%$ calcium chloride, and placed in an incubator for $30 \mathrm{~min}$ at $37^{\circ} \mathrm{C}$. After the contents are mixed carefully, the beaker was incubated at $37^{\circ} \mathrm{C}$ for $1 \mathrm{~h}$. During this time, the plasma fibrinogen, which is soluble, converts into fibrin, which is insoluble and viscous. After the incubation period, the fibrin membrane obtained is circular, with a diameter between 18 and $22 \mathrm{~mm}$, and approximately $1 \mathrm{~mm}$ thick. With these properties, the fibrin membrane is perfectly manageable and suitable for applying to the damaged ocular surface.

Combined autologous fibrin membrane and E-PRP clot has been used with success in our clinic and results have been published [47]. We included 11 patients with central corneal perforations caused by a chronic corneal ulcerative disorder. In three cases the perforation was partially blocked by intraocular tissue, particularly the iris. The epithelium was debrided with a sponge 1.0-1.5 $\mathrm{mm}$ from the perforation (Fig. 8). The fibrin membrane was then dried on an 

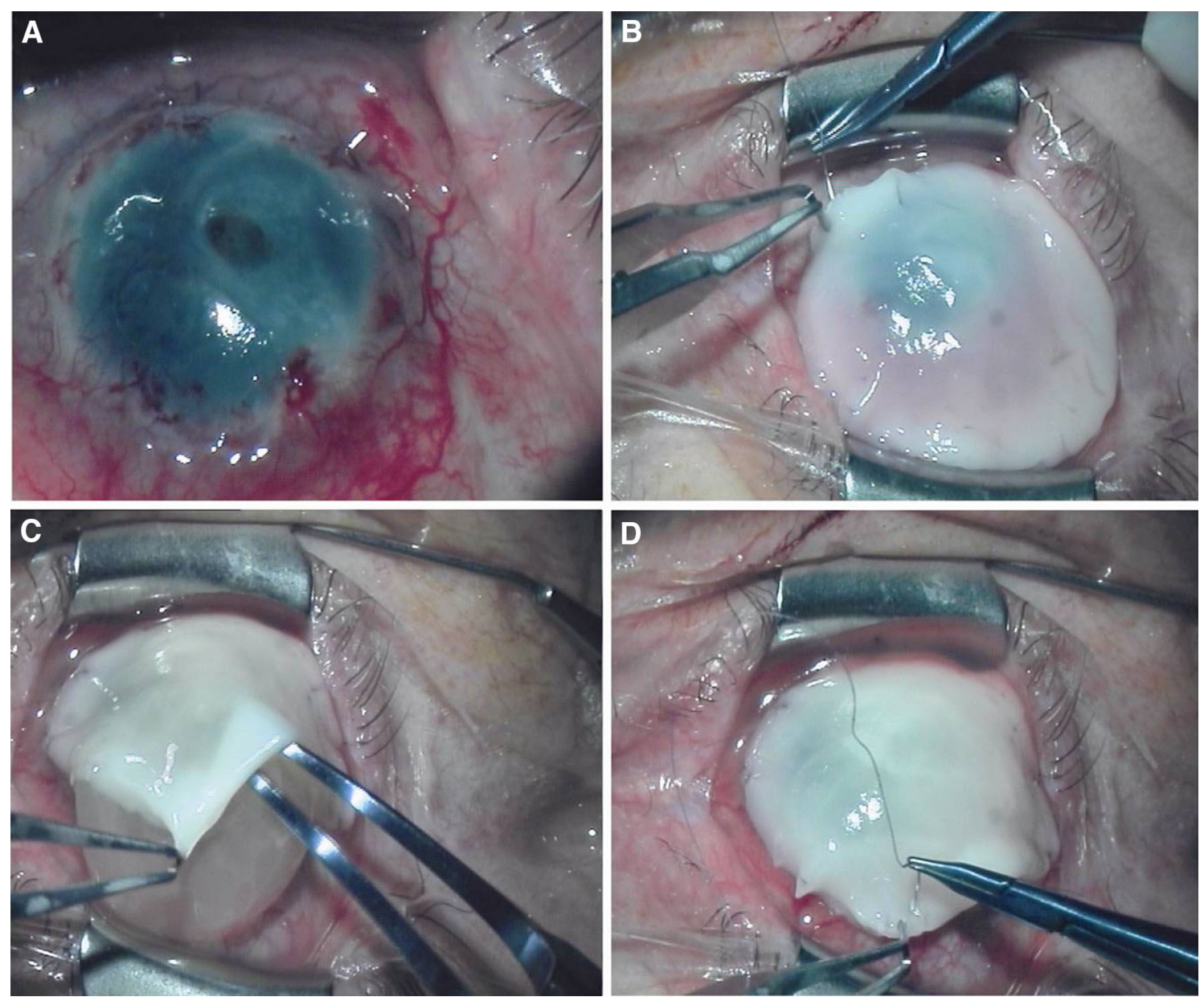

Fig. 8 Intraoperative steps of the surgical technique. a Large central corneal perforation. $\mathbf{b}$ The fibrin membrane clot is placed underneath the fibrin membrane. d The upper portion of the membrane is sutured to the conjunctiva

is extended over the perforated cornea and sutured to the inferior conjunctiva. $\mathbf{c}$ The eye platelet-rich plasma (E-PRP)

absorbent sterile paper until it appeared to be a solid, fibrous structure. A 10-0 nylon-running suture was used to sew the fibrin membrane to the $180^{\circ}$ inferior conjunctiva. Solid platelet-rich plasma clots were then placed onto the corneal perforation and the epithelial debrided area underneath the fibrin membrane. Additional stitches were used to fixate the fibrin membrane to the remainder of the conjunctiva. The fibrin and E-PRP clots were placed in the same manner when there was iris or other intraocular tissue blocking the perforation. A partial tarsorrhaphy was performed to allow observation of the central cornea with the slit lamp at the end of the procedure. In all cases, the corneal perforation was sealed. The fibrin membrane was present on the corneal surface for the first $3-5$ days and then gradually disappeared. No evidence of infection or inflammation was detected in any of the cases. Finger pressure confirmed the presence of acceptable levels of ocular tonus in all cases from day 2 after the operation. After 7 days, the tarsorrhaphy was removed from all patients and the ocular surface was inspected. In all cases the corneal perforation was sealed with no evidence of 

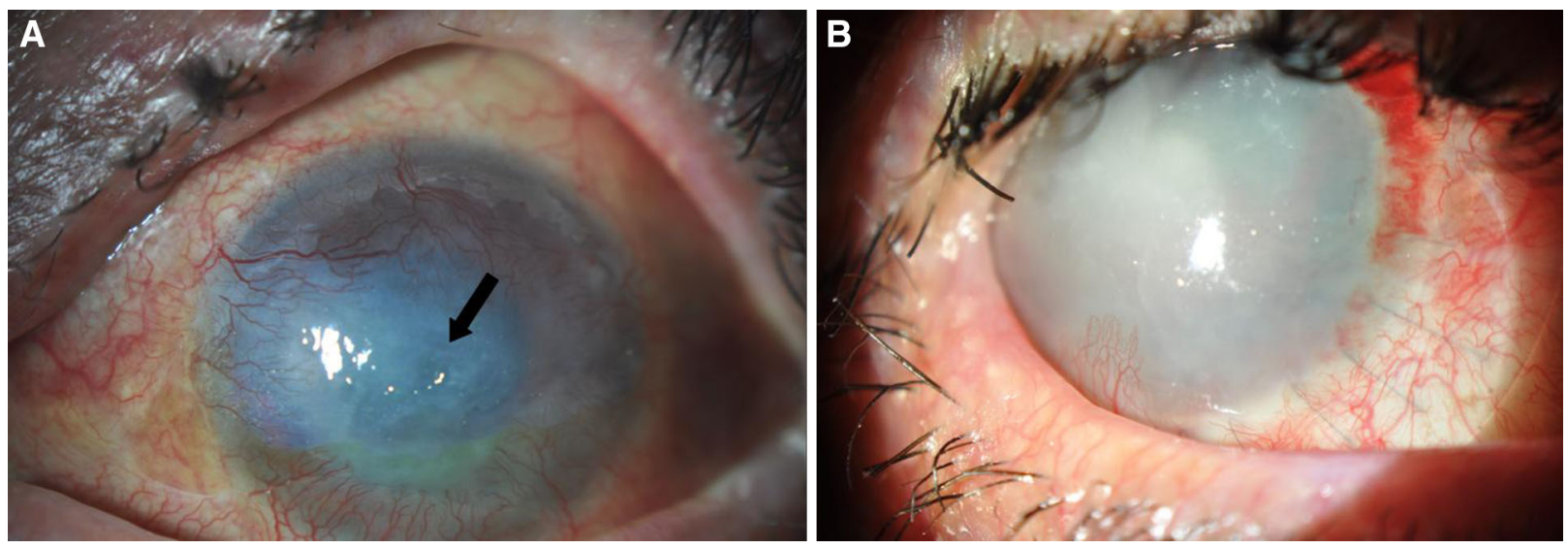

Fig. 9 a Corneal perforation before treatment. b The same eye 1 month after the combined use of eye platelet-rich plasma (E-PRP) clot and autologous fibrin membrane

leakage even when moderate pressure was applied to the globe (Fig. 9). No relapses of the ulcerative corneal condition or perforation occurred in any of the cases.

Our findings combined with research on this topic suggest that combined use of autologous fibrin membrane and E-PRP clot is a safe and effective alternative for the closure of corneal perforations. The obvious advantage of this technique is the use of autologous material for surgery. We believe that with specialized technicians and resources, the preparation of E-PRP and autologous fibrin membrane is possible in most tertiary hospitals.

\section{CONCLUSION}

Solid, platelet-enriched plasma in the form obtained in ophthalmology, E-PRP, is a reliable and effective surgical coadjuvant to promote corneal wound healing in severe corneal ulcers and corneal perforations, and may be associated to other, ocular surface reconstruction procedures. Solid E-PRP concentrates platelets in a small volume of plasma which contains a high concentration of essential growth factors and cell adhesion molecules. These growth factors and cell adhesion molecules occupy a major role in wound healing and enhance the physiological process at the site of the injury/surgery. Different materials are used to maintain the solid clot attached at the site where treatment is necessary. For these purposes, AM or other biomaterials such as bovine pericardium or autologous fibrin membrane can be used with different grades of interdonor variations or biological hazards, providing surgical alternatives to be used depending of the availability of them.

\section{ACKNOWLEDGMENTS}

All named authors meet the International Committee of Medical Journal Editors (ICMJE) criteria for authorship for this manuscript, take responsibility for the integrity of the work as a whole, and have given final approval for the version to be published.

Disclosures. Francisco Arnalich, Alejandra E. Rodriguez, Alvaro Luque-Rio and Jorge L. Alio have nothing to disclose. 
Compliance with Ethical Guidelines. This article is based on previously conducted studies and does not involve any new studies of human or animal subjects performed by any of the authors.

Open Access. This article is distributed under the terms of the Creative Commons Attribution-NonCommercial 4.0 International License (http://creativecommons.org/licenses/ by-nc/4.0/), which permits any noncommercial use, distribution, and reproduction in any medium, provided you give appropriate credit to the original author(s) and the source, provide a link to the Creative Commons license, and indicate if changes were made.

\section{REFERENCES}

1. Nakamura T, Inatomi T, Sotozono C, Koizumi N, Kinoshita S. Ocular surface reconstruction using stem cell and tissue engineering. Prog Retin Eye Res. 2016;51:187-207.

2. Hick S, Demers PE, Brunette I, La C, Mabon M, Duchesne B. Amniotic membrane transplantation and fibrin glue in the management of corneal ulcers and perforations: a review of 33 cases. Cornea. 2005;24(4):369-77.

3. Jhanji V, Young AL, Mehta JS, Sharma N, Agarwal T, Vajpayee RB. Management of corneal perforation. Surv Ophthalmol. 2011;56(6):522-38.

4. Alio JL, Rodriguez AE, WróbelDudzińska D. Eye platelet-rich plasma in the treatment of ocular surface disorders. Curr Opin Ophthalmol. $2015 ; 26(4): 325-32$.

5. Petznick A, Tong L, Chung R, Wang JC, Koh M, Salleh R, Waduthantri S. Autologous plasma eyedrops prepared in a closed system: a treatment for dry eye. Eye. 2013;27(9):1102.

6. Alio JL, Arnalich-Montiel F, Rodriguez AE. The role of "eye platelet rich plasma" (E-PRP) for wound healing in ophthalmology. Curr Pharm Biotechnol. 2012;13(7):1257-65.

7. Marx RE. Platelet-rich plasma (PRP): what is PRP and what is not PRP? Implant Dent. 2001;10(4):225-8.
8. Nugent RB, Lee GA. Ophthalmic use of blood-derived products. Surv Ophthalmol. 2015;60(5):406-34.

9. Anitua E, Sanchez M, Orive G, Andia I. Delivering growth factors for therapeutics. Trends Pharmacol Sci. 2008;29(1):37-41.

10. Anitua E, Andia I, Ardanza B, Nurden P, Nurden AT. Autologous platelets as a source of proteins for healing and tissue regeneration. Thromb Haemost. 2004;91(1):4-15.

11. Fox RI, Chan R, Michelson JB, Belmont JB, Michelson PE. Beneficial effect of artificial tears made with autologous serum in patients with keratoconjunctivitis sicca. Arthritis Rheum. 1984;27(4):459-61.

12. Tsubota K, Goto E, Shimmura S, Shimazaki J. Treatment of persistent corneal epithelial defect by autologous serum application. Ophthalmology. 1999;106(10):1984-9.

13. Matsumoto Y, Dogru M, Goto E, et al. Autologous serum application in the treatment of neurotrophic keratopathy.

2004;111(6):1115-20.

Ophthalmology.

14. Goto E, Shimmura S, Shimazaki J, Tsubota K. Treatment of superior limbic keratoconjunctivitis by application of autologous serum. Cornea. 2001;20(8):807-10.

15. Ogawa Y, Okamoto S, Mori T, et al. Autologous serum eye drops for the treatment of severe dry eye in patients with chronic graft-versus-host disease. Bone Marrow Transpl. 2003;31(7):579-83.

16. Noda-Tsuruya T, Asano-Kato N, Toda I, Tsubota K. Autologous serum eye drops for dry eye after LASIK. J Refract Surg. 2006;22(1):61-6.

17. Tsubota K, Satake Y, Ohyama M, et al. Surgical reconstruction of the ocular surface in advanced ocular cicatricial pemphigoid and Stevens-Johnson syndrome. Am J Ophthalmol. 1996;122(1):38-52.

18. Tsubota K, Shimazaki J. Surgical treatment of children blinded by Stevens-Johnson syndrome. Am J Ophthalmol. 1999;128(5):573-81.

19. Liu L, Hartwig D, Harloff S, et al. Corneal epitheliotrophic capacity of three different blood-derived preparations. Invest Ophthalmol Vis Sci. 2006;47(6):2438-44.

20. Anitua E, Sanchez M, Nurden AT, Nurden P, Orive G, Andia I. New insights into and novel applications for platelet-rich fibrin therapies. Trends Biotechnol. 2006;24(5):227-34. 
21. Nurden AT, Nurden P, Sanchez M, Andia I, Anitua E. Platelets and wound healing. Front Biosci. 2008;13:3532-48.

22. Anitua E, Andia I, Sanchez M, et al. Autologous preparations rich in growth factors promote proliferation and induce VEGF and HGF production by human tendon cells in culture. J Orthop Res. 2005;23(2):281-6.

23. Anitua E, Sanchez M, Nurden AT, et al. Platelet-released growth factors enhance the secretion of hyaluronic acid and induce hepatocyte growth factor production by synovial fibroblasts from arthritic patients. Rheumatology. 2007;46(12):1769-72.

24. Anitua E, Sanchez M, Zalduendo MM, et al. Fibroblastic response to treatment with different preparations rich in growth factors. Cell Prolif. 2009;42(2):162-70.

25. Alio JL, Abad M, Artola A, Rodriguez-Prats JL, Pastor S, Ruiz-Colecha J. Use of autologous platelet-rich plasma in the treatment of dormant corneal ulcers. Ophthalmol. 2007;114(7):1286-93.

26. Alio JL, Colecha JR, Pastor S, Rodriguez A, Artola A. Symptomatic dry eye treatment with autologous platelet-rich plasma. Ophthalmic Res. 2007;39(3):124-9.

27. Alio JL, Pastor S, Ruiz-Colecha J, Rodriguez A, Artola A. Treatment of ocular surface syndrome after LASIK with autologous platelet-rich plasma. J Refract Surg. 2007;23(6):617-9.

28. Anitua E. The use of plasma-rich growth factors (PRGF) in oral surgery. Pract Proced Aesthet Dent. 2001;13(6):487-93 (quiz 487-493).

29. Foster TE, Puskas BL, Mandelbaum BR, Gerhardt $\mathrm{MB}$, Rodeo SA. Platelet-rich plasma: from basic science to clinical applications. Am J Sports Med. 2009;37(11):2259-72.

30. Intini G. The use of platelet-rich plasma in bone reconstruction therapy. 2009;30(28):4956-66.

31. Anitua E, Orive G, Pla R, Roman P, Serrano V, Andia I. The effects of PRGF on bone regeneration and on titanium implant osteointegration in goats: a histologic and histomorphometric study. J Biomed Mater Res A. 2009;91(1):158-65.

32. Roldan JC, Jepsen S, Schmidt C, et al. Sinus floor augmentation with simultaneous placement of dental implants in the presence of platelet-rich plasma or recombinant human bone morphogenetic protein-7. Clin Oral Implants Res. 2004;15(6):716-23.
33. Garg AK, Gargenese D, Peace I. Using platelet-rich plasma to develop an autologous membrane for growth factor delivery in dental implant therapy. Dent Implantol Update. 2000;11(6):41-4.

34. Sanchez M, Anitua E, Azofra J, Aguirre JJ, Andia I. Intra-articular injection of an autologous preparation rich in growth factors for the treatment of knee OA: a retrospective cohort study. Clin Exp Rheumatol. 2008;26(5):910-3.

35. Sanchez M, Anitua E, Azofra J, Andia I, Padilla S, Mujika I. Comparison of surgically repaired Achilles tendon tears using platelet-rich fibrin matrices. Am J Sports Med. 2007;35(2):245-51.

36. Mazor Z, Peleg M, Garg AK, Luboshitz J. Platelet-rich plasma for bone graft enhancement in sinus floor augmentation with simultaneous implant placement: patient series study. Implant Dent. 2004;13(1):65-72.

37. Velich N, Nemeth Z, Hrabak K, Suba Z, Szabo G. Repair of bony defect with combination biomaterials. J Craniofac Surg. 2004;15(1):11-5.

38. Siebrecht MA, De Rooij PP, Arm DM, Olsson ML, Aspenberg P. Platelet concentrate increases bone ingrowth into porous hydroxyapatite. Orthopedics. 2002;25(2):169-72.

39. Lieberman JR, Daluiski A, Einhorn TA. The role of growth factors in the repair of bone. Biology and clinical applications. J Bone Joint Surg Am. 2002;84-A(6):1032-44.

40. Alsousou J, Thompson M, Hulley $\mathrm{P}$, Noble A, Willett K. The biology of platelet-rich plasma and its application in trauma and orthopaedic surgery: a review of the literature. J Bone Joint Surg Br. 2009;91(8):987-96.

41. Alio JL, Rodriguez AE, Martinez LM. Bovine pericardium membrane (Tutopatch) combined with solid platelet-rich plasma for the management of perforated corneal ulcers. Cornea. 2013;32(5):619-24.

42. Hopkinson A, McIntosh RS, Tighe PJ, James DK, Dua HS. Amniotic membrane for ocular surface reconstruction: donor variations and the effect of handling on TGF-beta content. Invest Ophthalmol Vis Sci. 2006;47(10):4316-22.

43. Us MH, Sungun M, Sanioglu S, et al. A retrospective comparison of bovine pericardium and polytetrafluoroethylene patch for closure of ventricular septal defects. J Int Med Res. 2004;32(2):218-21.

44. Filippi R, Schwarz M, Voth D, Reisch R, Grunert P, Perneczky A. Bovine pericardium for duraplasty: 
clinical results in 32 patients. Neurosurg Rev. 2001;24(2-3):103-7.

45. Schmal F, Basel T, Grenzebach UH, Thiede O, Stoll W. Preseptal transconjunctival approach for orbital floor fracture repair: ophthalmologic results in 209 patients. Acta Otolaryngol. 2006;126(4):381-9.

46. Gupta M, Lyon F, Singh AD, Rundle PA, Rennie IG. Bovine pericardium (Tutopatch) wrap for hydroxyapatite implants. Eye. 2007;21(4):476-9.

47. Alio JL, Rodriguez AE, Martinez LM, Rio AL. Autologous fibrin membrane combined with solid platelet-rich plasma in the management of perforated corneal ulcers: a pilot study. JAMA Ophthalmol. 2013;131(6):745-51.
48. Setlik DE, Seldomridge DL, Adelman RA, Semchyshyn TM, Afshari NA. The effectiveness of isobutyl cyanoacrylate tissue adhesive for the treatment of corneal perforations. Am J Ophthalmol. 2005;140(5):920-1.

49. Portnoy SL, Insler MS, Kaufman HE. Surgical management of corneal ulceration and perforation. Surv Ophthalmol. 1989;34(1):47-58.

50. Liu J, Sheha H, Fu Y, Liang L, Tseng SC. Update on amniotic membrane transplantation. Expert Rev Ophthalmol. 2010;5(5):645-61.

51. Nobe JR, Moura BT, Robin JB, Smith RE. Results of penetrating keratoplasty for the treatment of corneal perforations. Arch Ophthalmol. 1990;108(7):939-41. 